Nat. Hazards Earth Syst. Sci., 19, 389-397, 2019

https://doi.org/10.5194/nhess-19-389-2019

(C) Author(s) 2019. This work is distributed under the Creative Commons Attribution 4.0 License.

\title{
Estimations of rip current rescues and drowning in the United States
}

\author{
B. Chris Brewster ${ }^{1}$, Richard E. Gould ${ }^{1}$, and Robert W. Brander ${ }^{2}$ \\ ${ }^{1}$ United States Lifesaving Association, 1968 South Coast Highway no. 740, Laguna Beach, California 92651, USA \\ ${ }^{2}$ School of Biological, Earth and Environmental Sciences, UNSW Sydney, Sydney, NSW 2052, Australia
}

Correspondence: B. Chris Brewster (brewster@lifesaver1.com)

Received: 15 May 2018 - Discussion started: 25 June 2018

Revised: 5 December 2018 - Accepted: 17 December 2018 - Published: 22 February 2019

\begin{abstract}
Rip currents are the greatest hazard to swimmers on surf beaches, but due to a lack of consistent incident reporting in many countries, it is often difficult to quantify the number of rip-current-related rescues and drowning deaths occurring along surf beaches. This study examines this problem using rescue data reported to the United States Lifesaving Association (USLA) by surf beach rescuers from 1997 through 2016. These data were checked, corrected, and culled so that only data from surf beach rescue agencies that reported the primary cause of rescue were included. Results show that rip currents are the primary cause of $81.9 \%$ of rescues on surf beaches, with regional variation from $75.3 \%$ (East Coast) to $84.7 \%$ (West Coast). These values are significantly higher than those previously reported in the scientific literature (e.g., $36.5 \%, 53.7 \%$ ). Using this value as a proxy when examining overall surf beach drowning fatalities, it is suggested that more than 100 fatal drownings per year occur due to rip currents in the United States. However, it is clear that the United States data would benefit by an increase in the number of lifeguard agencies which report surf-related rescues by primary cause.
\end{abstract}

\section{Introduction}

On beaches around the world characterized by wave breaking activity across surf zones (herein referred to as "surf beaches"), it is well established that the primary cause of rescues conducted by lifeguards, as well as fatal drownings, is rip currents (e.g., Klein et al., 2003; Gensini and Ashley, 2010a; Brighton et al., 2013; Brander and Scott, 2016). Rip currents are strong and concentrated flows of water moving away from the shoreline that are driven by alongshore variability in wave breaking and energy dissipation (Castelle et al., 2016). They are complex and variable features that are manifest as diverse types, which can be both persistent and transient in occurrence and location, may occupy deeper channels between shallower sand banks, or may lack any morphologic expression at all and can occur along open stretches of beaches, both oceanic and lacustrine, or against hard structures such as headlands or piers (Castelle et al., 2016).

Typical rip currents are on the order of 5-50 m wide and extend to the seaward limit of the surf zone, where they may recirculate, or extend past the surf zone variable distances offshore (Castelle et al., 2016). Mean rip current flow speeds over sustained periods (hours) are on the order of 0.3$0.5 \mathrm{~ms}^{-1}$, but rips can experience short-lived pulsations of $2 \mathrm{~ms}^{-1}$ or more (MacMahan et al., 2006) making them a significant hazard to swimmers or waders of all swimming abilities who may find themselves caught in them. Inexperienced surfers and bodyboarders can also be imperiled by rip currents (Attard et al., 2015).

There has been a significant and recent increase in research relating to both physical and social aspects associated with the rip current hazard (e.g., Hatfield et al., 2012; Brannstrom et al., 2014; McCarroll et al., 2014; Scott et al., 2014; Castelle et al., 2016b; Houser et al., 2017). However, an ongoing challenge in addressing the actual societal and economic impact of the rip current hazard for beach safety practitioners, governments, and scientists alike is obtaining accurate values of the number of rip-current-related lifeguard rescues and fatal rip current drownings. In terms of the latter, two key factors make it impossible to determine the number of deaths caused by rip currents with complete accuracy.

First, it is well established that the majority of fatal rip current drownings occur on beaches unpatrolled by lifeguards or outside of seasonal or daily beach patrol times (Branche 
and Stewart, 2001; Brander and Scott, 2016; SLSA, 2017). In some of these incidents, there are simply no eyewitness accounts available to help determine the cause of drowning. In others, drowning deaths are observed, but by people lacking necessary awareness and understanding to correctly attribute the role (if any) of a rip current in a drowning.

Second, in many countries there are no national requirements for reporting the causal factors (such as rip currents) in coastal drowning deaths. Even in countries that do, such as Australia (Brighton et al., 2013) and Costa Rica (Arozarena et al., 2015), the documented number of rip current fatalities is likely underestimated for the reasons previously noted. For example, while Brighton et al. (2013) determined an average of 21 rip-current-related fatalities on Australian beaches per year, they emphasized that this value was an underestimate as it was based only on confirmed rip-current-related drowning deaths.

The United States, with thousands of kilometers of coastline affected by rip currents and hundreds of millions of beachgoers each year, presents a challenge in accurately determining the number of rip-current-related drownings that occur. There are five distinct coastal regions characterized by different wave climates and physical characteristics, such as geologic setting and beach type: (i) the continental Pacific West Coast; (ii) the Atlantic East Coast; (iii) the Gulf Coast; (iv) the coastlines of the Great Lakes; and (v) the Hawaiian Islands. Air and water temperature differences, as well as beach user demographics and beach usage, can also vary greatly among these regions, creating variable swimming seasons throughout the country

The complex forcing mechanisms associated with rip current formation, type, and location both within and between these regions not only lead to exposure to the rip current hazard being extremely variable spatially and temporally, but also make it difficult and laborious to provide a gross estimate of the occurrence and location of rip currents on United States beaches at any given time. Similarly, although some coastal US National Weather Service (NWS) offices receive daily reports on rip current activity from lifeguards to assist in evaluating and disseminating their public rip current hazard advisory (Houser et al., 2017; Moulton et al., 2017), these reports do not typically include the specific type, location, or number of rip currents.

Perhaps most importantly, as in other countries, the presence of lifeguards on US beaches is temporally and spatially variable. While some beaches have lifeguard beach patrols year round, and two (Los Angeles County and the city of San Diego) staff lifeguards $24 \mathrm{~h}$ a day, year round, others are staffed seasonally or are completely unstaffed (not patrolled). As such, there are many periods of time and beaches where lifeguards are absent. The breadth of services provided by US lifeguard agencies also varies tremendously. Some are staffed and funded as primary providers of public safety, with a variety of advanced training and equipment, such as oceangoing rescue vessels, 9-1-1 answering points, and advanced medi- cal training. Others provide more basic services with limited technology (Brewster, 2017).

Despite these challenges, several attempts have been made to quantify the number of rip-current-related fatalities on US beaches. Lushine (1991) combined documented rip current drowning fatalities in Florida, North Carolina, and Alabama with various nationwide drowning statistic databases to estimate that 150 rip-current-related fatalities occur each year nationally. Gensini and Ashley (2010a) used LexisNexis, an online archive of newspaper articles sourced from local and national newspapers, combined with the National Climatic Data Center's (NCDC) Storm Data (now known as Storm Events) database (which uses a wide variety of sources from emergency management officials to newspaper clipping services), to conclude that on average 35 people die from rip currents in the US each year. In contrast the United States Lifesaving Association (USLA) has estimated that rip current fatalities in the US can exceed 100 per year.

The USLA estimate was arrived at internally in 2004 through a two-step process outlined in documentation submitted to the National Weather Service that is provided here as Supplement. First, the number of deaths each year at surf beaches was estimated based on several published studies. Second, the USLA theorized that the percentage of rescues from drowning due to rip currents, based on reports by lifeguards at surf beaches (then found to be over $80 \%$ ), is a proxy for the relative proportion of surf drowning fatalities due to rip currents (in the absence of rescue) and applied that percentage to the total number of estimated surf beach deaths (see Supplement). The discrepancies among these three estimates bear further evaluation.

Since 1966, the USLA has been soliciting annual data from beach lifeguard agencies and other water rescue agencies around the country, including the number of rescues from drowning, the cause of those rescues, the number of medical aids provided, drowning fatalities, estimated attendance, and many other data points. Lifeguard agencies are managed independently of the USLA, which sets recommended operational guidelines. These agencies are only obligated to report annual statistics to the USLA if they are certified (accredited) by the USLA, although they are welcome to report regardless of certification status. The USLA is the only national group collecting these data. Most, though not all, water rescue agencies reporting data to the USLA serve surf beaches where rip currents are present. In 2016, the final year of data included in this study, there were 150 USLAcertified agencies nationwide, varying in size from Los Angeles County and California State Parks on the large side (over 700 lifeguards each) to very small agencies with as few as 10 lifeguards. There are many other US water rescue agencies (the specific number is unknown) that do not report data to the USLA.

As noted, one of the data points collected by the USLA is rescues from drowning, including those from rip currents. Those reporting are surf lifeguards trained to identify and 
rescue people from distress in rip currents. As noted earlier, the USLA, based on an evaluation of the data it collects, has consistently reported over many years that the primary cause of over $80 \%$ of rescues from drowning by lifeguards at surf beaches is rip currents and that in some areas this proportion is higher. However, two independent published studies have reviewed USLA data and come to different conclusions from the USLA regarding the percent of rip-current-related rescues. Gensini and Ashley (2010b) reviewed the USLA data from 2000 to 2009 and concluded that roughly $36.5 \%$ of rescues reported to the USLA in those years were due to rip currents. Brighton et al. (2013) reviewed the USLA data from 2005 to 2011 and concluded that $53.7 \%$ of the rescues reported to the USLA were due to rip currents. Thus, three sources, reviewing similar data, although during different time periods, have come to widely varying conclusions about what the data collected and reported by the USLA show (Brewster, 2010; Brewster and Gould, 2014).

\section{Aim of this study}

Rescues from rip currents at beaches where lifeguards are present and report their data can provide insight into the magnitude of the hazard and may be useful as a proxy for the percent of drowning deaths at surf beaches. The primary aim of this study is, therefore, to accurately evaluate and report the percentage of rescues from rip currents by lifeguards reporting to the USLA. An additional aim is to determine why researchers have come to vastly different conclusions as to what the USLA data show and comment on the USLA estimate that rip-current-related drowning fatalities in the US exceed 100 per year.

\section{The United States Lifesaving Association Dataset}

The USLA refers to itself as "America's nonprofit professional association of beach lifeguards and open water rescuers" (USLA, https://www.usla.org, last access: 14 February 2018). The USLA does not directly train or certify beach lifeguards, but rather promulgates training standards and certifies (accredits) lifeguard providers (agencies) that choose to apply and are found to meet USLA requirements. These lifeguard agencies are typically funded by federal, state, and local governments, as well as a few private entities, some working as contractors to governments.

Many public and private beach lifeguard agencies in the United States record work output and beach observations in a manner similar to that of police and fire agencies. The resulting data offer measures of the services provided and help guide staffing and budgeting decisions. Each year many lifeguard agencies report these data to the USLA. In the final year of this study (2016), 148 agencies reported. These rescue reports vary in magnitude from Los Angeles County, which reported 12956 rescues from drowning that year, to much smaller agencies that reported as few as 1 rescue (USLA, 2018).

The USLA has suggested a variety of metrics that should be used by beach lifeguard agencies to encourage overall consistency of reporting. These metrics include actual work output, such as rescues from drowning and medical aids performed, drowning deaths, and many other data points. They also include estimates of beach attendance. Annual summaries and the underlying data provided to the USLA are published and made freely available at https://www.usla.org/ page/statistics (last access: 14 February 2018).

One of the key data points reported to the USLA is the number of rescues from drowning. For purposes of reporting, the USLA defines rescues as, "Total persons who are judged to be in imminent peril and brought to safety by a lifeguard. Usually involves physical contact. Does not include people who are given oral instructions to move to a safer location." (USLA, 2018).

The USLA also encourages agencies to document and report the primary cause of distress that led to the rescue. The primary cause reporting options for rescues include "surf", "rip current", "scuba", and "swiftwater". Agencies may choose none of these if they do not categorize the primary cause of rescue or if none of these categories apply to a given rescue. Surf refers to rescues in response to people who find themselves in distress due to the action of breaking waves or being out of depth. Rip current refers to rescues in response to people caught in rip currents. Scuba refers to rescues involving scuba divers. Swiftwater refers to people in distress in inland areas due to, for example, river flooding, and are therefore not rip current related.

Data on rescues are typically tabulated in rescue reports by the lifeguards who effect the rescues. USLA training materials include extensive information on identifying rip currents and rescuing people in peril from rip currents (Brewster, 2017). The rescue reports are compiled by the agencies and subsequently reported annually, via an online reporting system, to the USLA. Prior to the initiation of an online reporting system, reports were submitted manually via mail or email. The transition to electronic reporting occurred gradually, beginning in the late 1990s.

One of the challenges for reviewers of data reported to the USLA is that reporting lifeguard agencies are under no obligation to tabulate or report the primary cause of distress that led to the rescue. For example, in a given year one agency might report 50 rescues broken down by primary cause, but another agency may simply only report 50 rescues (no primary cause). If the total number of reported rescues for the year is compared to the total number in which rip currents were identified as the primary cause, without factoring out those agencies that failed to report a primary cause, then the actual proportion of rescues related to rip currents (or other primary causes) is diluted.

A second challenge for reviewers of USLA data is that some reporting agencies are solely responsible for inland ar- 
eas, such as reservoirs and rivers, where surf and rip currents are not present (the Great Lakes, where rip currents can occur, are an exception). Nevertheless, these agencies' total rescue numbers are included in the total number of rescues in any given year. For reasons similar to primary cause reporting, if the total number of reported rescues for a given year is compared to the total number in which rip currents were identified as the primary cause, without factoring out those agencies that serve beaches without rip currents, then the proportion of rescues related to rip currents is further diluted.

A third challenge for reviewers of the USLA data is that some agencies oversee both surf and inland areas, but report totals of all rescues at both venues (and the underlying causes). One example is the city of San Diego, which reports thousands of rescues each year including some (albeit a small number) that occur in Mission Bay, which is a lowenergy estuarine environment with no surf conditions or rip currents. Similarly, California State Parks oversee lifeguards at both surf beaches and inland lakes (including reservoirs), including them all in a total number of rescues (and underlying causes).

In determining the percent of rescues attributable to rip currents at surf beaches, it is necessary to exclude rescue reports from agencies that do not identify the primary cause of the rescue and to exclude, to the greatest extent possible, rescue reports from inland areas where rip currents are not present. If these steps are not taken in data evaluation, the percent of rip-current-related rescues will be misrepresented. Avoiding this misrepresentation requires both an in-depth review of the data and knowledge of which reporting agencies serve only inland areas. Even then, for the hybrid agencies that cover both inland and surf, it is not possible to exclude the inland rescue data because they are not separately reported. A goal of this study is to attempt to eliminate factors in the USLA rescue dataset that artificially underrepresent the impact of rip currents on rescues and drowning.

\section{Methodology}

Analysis of USLA rescue data was restricted to the most recent 20 years of compiled data from 1997 to 2016. Data were first checked and corrected for any errors and anomalies. For example, there were several isolated examples where data from one agency appeared twice in a given year, and in a few other cases, the total addition of yearly rescues was found to be mathematically incorrect. These turned out to be minor and did not affect the overall data outputs significantly. As a typical example, a double reporting of data by an agency in 2002 increased the total number of rescues by 10 , but this was only $0.021 \%$ of the total number of rescues in the year.

The dataset was then culled using objective decision rules. Specifically, as the purpose was to examine rip current rescues on surf beaches, rescue data from any agency oversee- ing a body of water that did not include surf beaches were removed. While the Great Lakes represent one of the five coastal regions in the US and are subject to physical forcing mechanisms that can generate rip currents, they were not included in further analysis since, with one minor exception, rescue data from the Great Lakes do not include primary cause of rescue.

Lifeguard agencies in other coastal regions that did not report a primary cause of rescues were also removed. This, unfortunately, resulted in removal of the entire dataset of Los Angeles County, which normally reports the largest number of rescues of any beach agency. It was found that in a typical year this is more than $15 \%$ of all rescues reported to the USLA. However, a random sampling of agencies reporting in Orange County (to the immediate south of Los Angeles County) found rip currents to be the primary cause in $83 \%$ of rescues from drowning. This is comparable to all West Coast agencies, so it appears likely that if Los Angeles County were to report, it would report similar values.

Figure 1 shows the total number of agencies reporting for each year and the excluded agencies (those with no primary cause being reported or non-surf beach agencies). Agencies with both surf and non-surf beaches were included if they reported a primary cause, despite the inevitable, unknown degree of overall dilution of rip currents as a primary cause. Any reports of rescues due to the swiftwater rescue cause were removed from consideration since, by definition, they do not occur at surf beaches. In general, the number of included surf agencies that report primary cause has increased over time, while the number of excluded agencies has remained relatively constant.

Where scuba was listed as the primary cause, the rescues were included, as these rescues can and do take place in surf environments. In these cases, as in others, the primary cause is up to the determination of the reporting rescuer. That is, for example, a scuba diver may be rescued due to complications from scuba diving, from being caught in a rip current, or both. The primary cause is what is to be reported and what we rely on here.

\section{Results and discussion}

Primary causes of surf beach rescues conducted for the period 1997-2016 for all included reporting agencies in the US were geographically separated into East, West, and Gulf coasts, as well as the Hawaiian Islands (Table 1). As described previously, the Great Lakes were not included because, with one minor exception, no agency from the Great Lakes reported a primary cause. In general, the percent of rescues caused by distress due to rip currents ranged from $75.3 \%$ (East Coast) to $84.7 \%$ (West Coast), with a long-term average across all regions of $81.9 \%$.

Figure 2a shows the gross reporting of the primary cause of rescues for included agencies during the period 1997- 


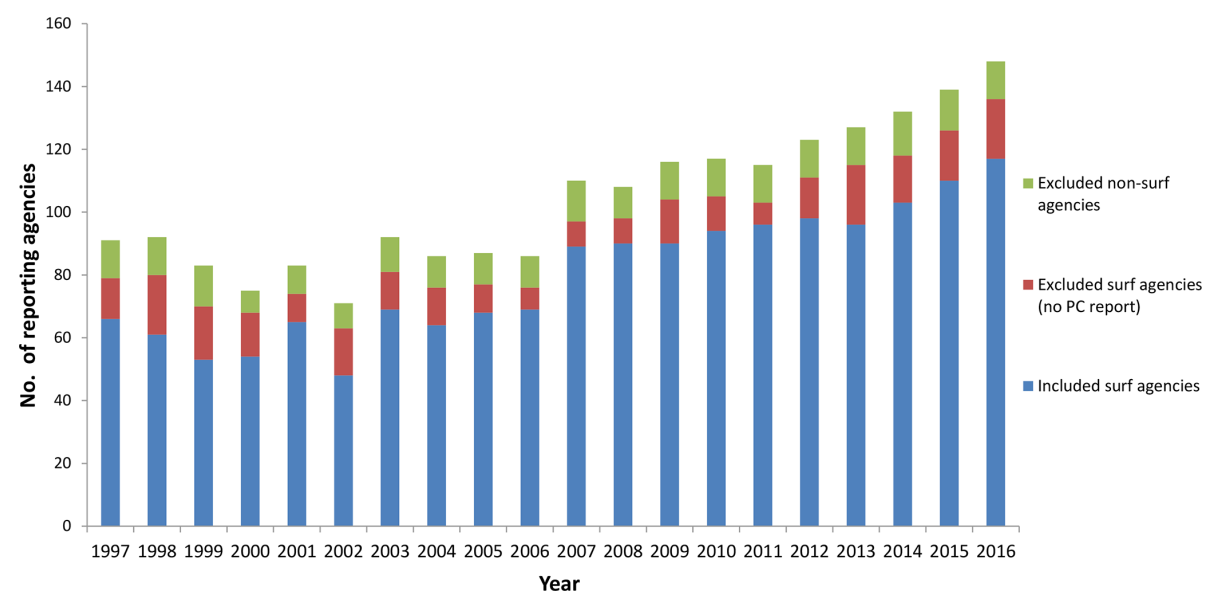

Figure 1. The number of lifeguard agencies reporting to the United States Lifesaving Association (USLA) statistics database between 1997 and 2016. Included surf agencies report primary cause (PC) of rescues.

Table 1. Primary causes of rescues on surf beaches reported to the USLA statistic database in 1997-2016 by coastal region in the US. The percent of rescues by primary cause are indicated in parentheses. The Great Lakes are not included as, with one minor exception, rescue data from the Great Lakes do not include primary cause of rescue.

\begin{tabular}{lrrrrr}
\hline \multicolumn{7}{c}{ Rescues by region } \\
\hline Region & All & Rip current & Surf & Scuba & Other \\
\hline East Coast & 233167 & $175572(75.3)$ & $50135(21.5)$ & $227(0.1)$ & $7233(3.1)$ \\
West Coast & 608041 & $514935(84.7)$ & $65349(10.7)$ & $4288(0.7)$ & $23469(3.9)$ \\
Gulf Coast & 15154 & $11876(78.4)$ & $3157(20.8)$ & $16(0.1)$ & $105(0.7)$ \\
Hawaiian Islands & 47191 & $37632(79.7)$ & $7262(15.5)$ & $150(0.3)$ & $2147(4.5)$ \\
Total & 903553 & $740015(81.9)$ & $125903(13.9)$ & $4681(0.5)$ & $322954(3.6)$ \\
\hline
\end{tabular}

2016, and while the number of rescues for all primary causes clearly fluctuates temporally, as evident in Fig. 2b, this is largely due to the increase in reporting agencies over this time. As is also evident in Fig. 2b, the percentage of total rip current rescues as the primary cause of all rescues nationally varies annually from $75.7 \%$ (2005) to $85.1 \%$ (1999) with no clear temporal trend apparent. There are many factors involved that can impact the number of rip current rescues that occur in a given year, including weather conditions, surf conditions, number of rip currents present, and beach visitation numbers. However, overall, even if the rip rescue data are normalized by the number of reporting lifeguard agencies, the number of surf rescues attributable to rip currents does not vary greatly over time.

\subsection{Underestimating rip current rescues}

Brighton et al. (2013) reviewed a smaller cohort of USLA data (2005-2011) and determined that only $53.7 \%$ of rescues were related to rip currents, which is significantly lower than the estimates derived here. The difference can be attributed to Brighton et al. (2013) using gross rescue totals in the USLA data, without excluding agencies that did not report a primary cause, agencies at beaches without surf, and swiftwater res- cues. Our examination of the same data in this way yields a result of $54.9 \%$, which is very close to the value reported by Brighton et al. (2013) and suggests that their estimate significantly underestimates the percent of rescues attributable to rip currents in the US.

Another aspect of the data reporting by Brighton et al. (2013) reveals some of the challenges involved in the reporting of rip current rescues in general. In reviewing Australian lifeguard and lifesaver rescue data provided by Surf Life Saving Australia (SLSA), Brighton et al. (2013) found that just $57.4 \%$ were attributable to rip currents. While they removed rescue reports "known to be in areas unaffected by rips" (as done in our study), they were only able to report on data relating to "major rescues," which are cases where "treatment is required" post-rescue and only make up $1.4 \%$ of all rescues reported by SLSA. The reason for this is that these were the only incidents in the dataset where a primary cause of rescue was sometimes reported (there was no requirement to include this information, so it was presumably unmentioned in some reports). Thus, they represent unusual and extreme cases and likely also greatly underestimate the actual percentage of rescues on Australian surf beaches caused by rip currents. Of note, the US data from agencies 
(a)

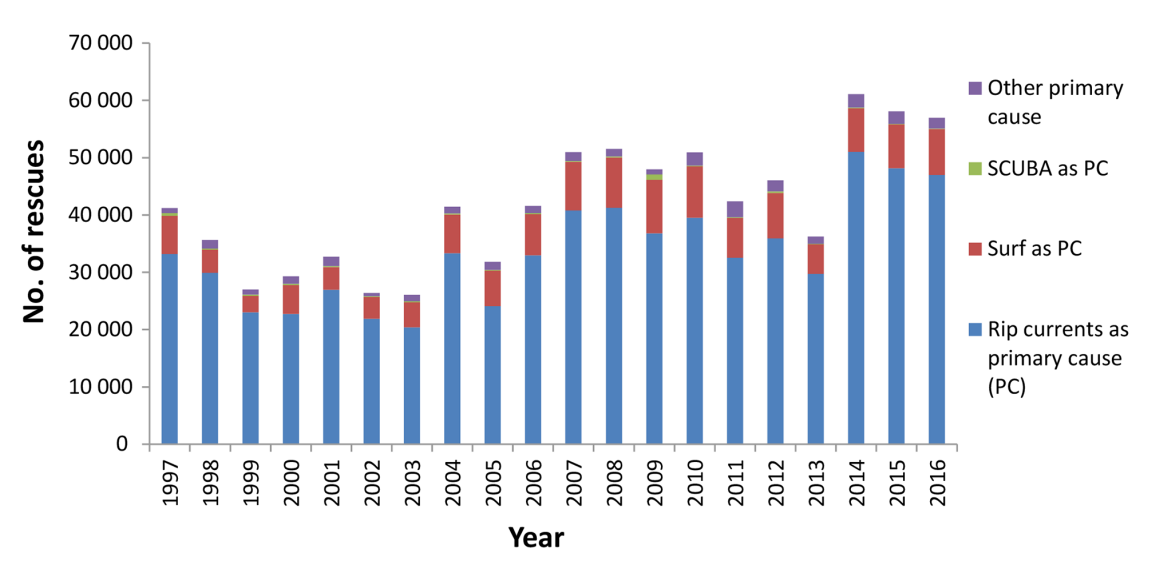

(b)

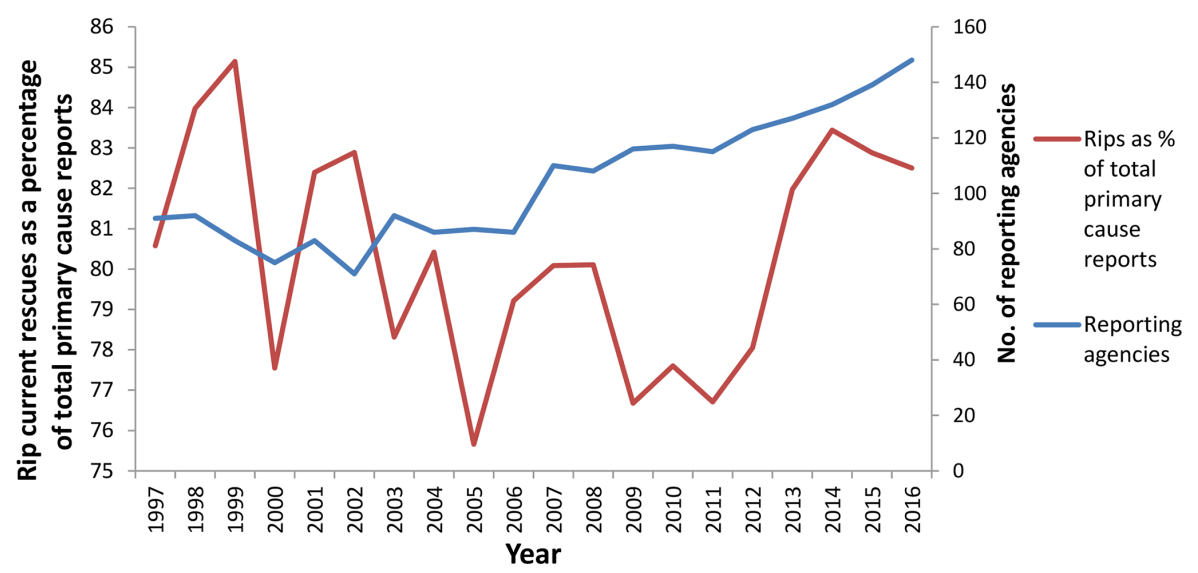

Figure 2. (a) Total rescues reported to the USLA by primary cause over the period 1997-2016. (b) Percentage of rip current rescues as primary cause and the number of lifeguard reporting agencies to the USLA over the period 1997-2016.

reporting a primary cause include $100 \%$ of rescues, whether major or routine.

Other discrepancies involving the USLA dataset are presented in Gensini and Ashley (2010b), who reviewed USLA data for the years 2000-2009 and suggested that only 36.5\% of rescues on US beaches were attributed to rip currents, which is less than half of the $75 \%-84 \%$ range reported here. We reviewed the data published on the United States Lifesaving Association website for these same years. Even when using gross data, without excluding data from agencies that did not report a primary cause and agencies from areas serving areas without surf, we found that $53 \%$ would appear to be attributable to rip currents, which is similar to the value reported by Brighton et al. (2013) for overlapping years. We then reviewed all of the years of USLA data for our study period without correcting for agencies that did not report a primary cause of the rescue and agencies at beaches without surf. The percent of rescues related to rip currents was found to be $49 \%$. This is quite similar to the conclusions of Brighton et al. (2013), but significantly higher than that of
Gensini and Ashley (2010b), and it remains uncertain how their value of $36.5 \%$ was attained.

\subsection{Rip current rescues and fatalities}

As described in the Introduction, some discrepancy also exists regarding estimates of annual average rip-current-related drowning fatalities in the US, with reported values ranging from 35 (Gensini and Ashley, 2010a) to more than 100 (USLA - see Supplement) and as high as 150 (Lushine, 1991). It is important to note that all of these values are estimates, as there is no comprehensive US national database for surf beach drowning fatalities. The closest attempt at this is by the US National Weather Service, which posts reports of US surf zone fatalities at https://www.weather.gov/safety/ ripcurrent-fatalities17 (last access: 4 December 2018) and includes an annual average number of reported rip-currentrelated drowning fatalities between 2013 and 2017 of 62 per year. 
According to the NWS (John Kuhn, personal communication, 2018) the primary source of these data is media reports, with some input from emergency management and water rescue officials. Of note, the website states, "Accurately tracking these types of fatalities is difficult because so many go unreported and undocumented." As an example of this difficulty, in 2016 the NWS reported a total of 108 surf zone fatalities, but in that same year surf rescue agencies reported 145 drowning fatalities solely within their jurisdictions to the USLA. This is a global problem.

As noted earlier, the USLA has theorized the percent of rescues from drowning in rip currents as a proxy for the percentage of drowning deaths at surf beaches in the absence of rescue. To examine this approach in more detail, we chose to review the most recent 5-year period (2012-2016) of drowning fatality reports from surf rescue agencies reporting to the USLA, since during this period the number of reporting agencies is the highest historically, ranging from 111 in 2012 to 136 in 2016 (Fig. 1). Of note, these agencies report drowning fatalities in both guarded areas (those under active lifeguard surveillance at the time of the drowning death) and unguarded areas (those within the jurisdiction of the agency, but not under lifeguard surveillance at the time of the death), and during this period an average of 109.6 drowning deaths per year were reported.

If we apply the long-term national average of $81.9 \%$ of rip-current-related rescues (Table 1) to the actual reports of drowning deaths (109.6 per year) from surf rescue agencies, it can be hypothesized that an average of 89.8 deaths per year were likely due to rip currents in the jurisdictions of the reporting agencies. This value is both higher than the estimate of 62 per year from the NWS and close to the previous estimate of "more than 100" by the USLA (see Supplement).

The authors estimate that less than $5 \%$ of the US coastline lies within the jurisdiction of surf rescue agencies which report to the USLA. While these agencies tend to oversee highly attended beach areas (e.g., Southern California, Florida, and Hawaii), many drowning deaths outside these areas are reported each year. Thus, relying only on drowning fatality reports from these agencies will understate the number of surf drowning deaths by an unknown but potentially significant number.

\subsection{Limitations and value of the USLA dataset}

There are clear limitations in the USLA data, some of which have been described here previously. Not all surf beach lifeguard agencies in the US report rescue data to the USLA, and some that do report do not report a primary cause. Additionally, the dataset is limited in that it cannot be demonstrated to represent a proportional exposure, on a per visitor basis, to rip currents on all beaches of the US. We therefore agree with Brighton et al. (2013) that the collection of drowning data using consistent categories and the routine collection of rip current information will allow for more accurate global compar- isons. If beach lifeguard agencies worldwide used consistent reporting data points and reported on the primary cause, including rip currents, for all rescues, beach safety practitioners would be better able to determine the impact of the rip current hazard globally and develop public awareness and education strategies accordingly (Houser et al., 2017). This is certainly true of the surf beach reporting situation in the United States.

The value of the USLA dataset is that it is the largest single repository in the world of data related to causation of distress at surf beaches. For example, an average of 83436 rescues from drowning per year were reported to the USLA over the 5-year period 2012-2016 for a total of 417180 rescues, most with a primary cause denoted. While the USLA has shared these data publicly, this study has shown that without a full understanding of the individual, underlying data sources, researchers may have difficulty making necessary and accurate conclusions. In response to values reported in previous studies, it is hoped that this study now provides a clearer representation of the USLA dataset in regard to the rip current hazard.

\section{Conclusions and recommendations}

An examination of rescue data reported by surf lifeguards in the United States to the United States Lifesaving Association has shown that rip currents are the primary cause of between $75.3 \%$ and $84.7 \%$ of all surf rescues on regional American beaches, with a 20 -year average of $81.9 \%$, a significantly higher estimate than previously reported in the scientific literature. Using the percentage of rip current rescues as a proxy to estimate the number of annual drowning deaths attributable to rip currents in the US suggests a value of 90 solely within the limited jurisdictions of surf rescue agencies reporting to the USLA. Thus, an annual figure of over 100 nationwide is not unreasonable.

Considering the number of US lifeguard agencies that fail to report a primary cause of rescue, it is recommended that the United States Lifesaving Association communicates with these lifeguard agencies to endeavor to increase the level of reporting of surf-related rescues by primary cause. It would also be desirable for a range of consistent and comprehensive data, involving both physical, environmental, and beach conditions and demographic beachgoer characteristics, to be reported by lifeguards. However, it is well established that data collection for beach lifeguards is difficult (Williamson et al., 2006; Harada et al., 2011; Morgan et al., 2013) for a variety of logistical and personal factors and is the fundamental challenge in balancing the tasks of providing water safety vigilance, rescue capability, and data collection, the former of which should not be compromised.

Nevertheless, it is vital to continue to work toward developing increasingly accurate estimates of both rip-currentrelated rescues and drowning deaths so that local gov- 
ernments, public policymakers, tourism authorities, public health professionals, and funders of mitigation measures understand that rip currents are by far the greatest health hazard related to those entering the water at surf beaches. Through this awareness, appropriate resources such as the provision of additional lifeguard services and development of public education programs can be justified and implemented to assist in drowning prevention.

Data availability. This work relied entirely on data published in a publicly available database by the United States Lifesaving Association on its website at https://www.usla.org/page/statistics (last access: 14 February 2018).

Supplement. The supplement related to this article is available online at: https://doi.org/10.5194/nhess-19-389-2019-supplement.

Author contributions. RG conducted the primary review of the data, with review and oversight of $\mathrm{BCB}$ and $\mathrm{RB}$. BCB and RB prepared the manuscript with contributions from RG.

Competing interests. B. Chris Brewster is a long-time volunteer official with the United States Lifesaving Association in various unpaid positions. Richard E. Gould is a long-time volunteer official with the United States Lifesaving Association, primarily overseeing the gathering and publication of the statistics referenced herein. Robert W. Brander declares that he has no conflict of interest.

Acknowledgements. We thank the United States Lifesaving Association for funding the gathering and publishing of statistics over many years, as well as funding aspects of this study. We thank the beach lifeguards and lifeguard agencies of America, without whose meticulous reporting this study would not be possible. We thank the reviewers for their insightful comments, which led to valuable improvements.

Edited by: Mauricio Gonzalez

Reviewed by: Michael Slattery and one anonymous referee

\section{References}

Arozarena, I., Houser, C., Echeverria, A. G., and Brannstrom, C.: The rip current hazard in Costa Rica, Nat. Hazards, 77, 753-768, 2015.

Attard, A., Brander, R. W., and Shaw, W. S.: Rescues conducted by surfers on Australian beaches, Accident Anal. Prev., 82, 70-78, 2015.

Branche, C. M. and Stewart, S. (Eds.): Lifeguard effectiveness: A report of the working group, Atlanta: Centers for Disease Control and Prevention, National Center for Injury Prevention and Control, 2001.
Brander, R. W. and Scott, T.: Science of the rip current hazard, in: The Science of Beach Lifeguarding: Principles and Practice, CRC Press, Boca Raton, 67-85, 2016.

Brannstrom, C., Trimble, S., Santos, A., Brown, H. L., and Houser, C.: Perception of the rip current hazard on Galveston Island and North Padre Island, Texas, USA, Nat. Hazards, 72, 1123-1138, 2014.

Brewster, B. C.: Rip current misunderstandings, Nat. Hazards, 55, 161-162, 2010.

Brewster, B. C. and Gould, R.: Comment on "Rip current related drowning deaths and rescues in Australia 2004-2011" by Brighton et al. (2013), Nat. Hazards Earth Syst. Sci., 14, 22032204, https://doi.org/10.5194/nhess-14-2203-2014, 2014.

Brewster B. C. (Ed.): Open Water Lifesaving: The United States Lifesaving Association Manual. New York, NY: Pearson Education, Inc., 2017.

Brighton, B., Sherker, S., Brander, R., Thompson, M., and Bradstreet, A.: Rip current related drowning deaths and rescues in Australia 2004-2011, Nat. Hazards Earth Syst. Sci., 13, 10691075, https://doi.org/10.5194/nhess-13-1069-2013, 2013.

Castelle, B., Scott, T., Brander, R. W., and McCarroll, R. J.: Rip current types, circulation and hazard, Earth Sci. Rev., 163, 1-21, 2016a.

Castelle, B., McCarroll, R. J., Brander, R. W., Scott, T., and Dubarbier, B.: Modelling the alongshore variability of optimum rip current escape strategies on a multiple rip-channelled beach, Nat. Hazards, 81, 664-686, 2016b.

Gensini, V. and Ashley, W.: An examination of rip current fatalities in the United States, Nat. Hazards, 54, 159-175, 2010a.

Gensini, V. and Ashley, W.: Reply to "Rip Current Misunderstandings" (Short Communication), Nat. Hazards, 55, 163-165, 2010b.

Harada, S. Y., Goto, R. S., and Nathanson, A. T.: Analysis of lifeguard-recorded data at Hanauma Bay, Hawaii, Wild. Env. Med., 22, 72-76, 2011.

Hatfield, J., Williamson, A., Sherker, S., Brander, R. W., and Hayen A.: Development and evaluation of an intervention to reduce rip current related beach drowning Accident, Anal. Prev., 46, 45-51, 2012.

Houser, C., Trimble, S., Brander, R., Brewster, B. C., Dusek, G., Jones, D., and Kuhn, J.: Public perceptions of a rip current hazard education program: "Break the Grip of the Rip!", Nat. Hazards Earth Syst. Sci., 17, 1003-1024, https://doi.org/10.5194/nhess17-1003-2017, 2017.

Klein, A., Santana, C., Diehl, E., and De Menezes, J.: An analysis of hazards associated with sea bathing: Results of five years work in oceanic beaches of Santa Catarina State, southern Brazil, J. Coastal Res., 35, 107-116, 2003.

Lushine, J. B.: A study of rip current drownings and related weather factors, Natl. Weather Digest., 16, 13-19, 1991.

MacMahan, J., Thornton, E., and Reniers, A.: Rip current review, Coast. Eng., 53, 191-208, 2006.

McCarroll, R. J., Brander, R. W., Macmahan, J. H., Turner, I. L., Reniers, A. J. H. M., Brown, J., Bradstreet, A., and Sherker, S.: Evaluation of swimmer-based rip current escape strategies, Nat. Hazards, 71, 1821-1846, 2014.

Morgan, D. and Ozanne-Smith, J.: Surf lifeguard rescues, Wild. Env. Med., 24, 285-290, 2013. 
Moulton, M., Dusek, G., Elgar, S., and Raubenheimer, B.: Comparison of rip current hazard likelihood forecasts with observed rip current speeds, Weather Forecast., 32, 1659-1666, 2017.

Scott, T., Masselink, G., Austin, M. J., and Russell, P.: Controls on macrotidal rip current circulation and hazard, Geomorphology, 214, 198-215, 2014.
Surf Life Saving Australia (SLSA): National Coastal Safety Report 2015, Sydney: Surf Life Saving Australia, 2017.

United States Lifesaving Association (USLA): American Lifeguard Rescue and Drowning Statistics for Beaches, available at: https: //www.usla.org/page/statistics, last access: 14 February 2018.

Williamson, A.: Feasibility study of a water safety data collection for beaches, J. Sci. Med. Sport, 9, 243-248, 2006. 